\title{
LXI. Researches in acoustics
}

\section{Alfred M. Mayer}

To cite this article: Alfred M. Mayer (1876) LXI. Researches in acoustics, Philosophical Magazine Series 5, 2:14, 500-507, DOI: 10.1080/14786447608639144

To link to this article: http://dx.doi.org/10.1080/14786447608639144

$$
\text { 曲 Published online: } 13 \text { May } 2009 .
$$

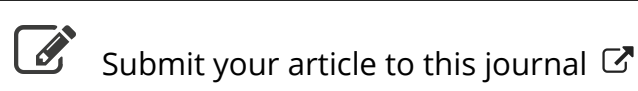

\footnotetext{
Цll Article views: 6
}

Q View related articles $\longleftarrow$

4 Citing articles: 9 View citing articles 


\section{[ 500 ]}

\section{Researches in Acoustics.}

By Alfred M. MAter *.-No. VIII.

[Continued from 4 th Series, vol. xlix. p. 432.]

\section{Contents.}

1. On the Obliteration of the Sensation of one Sound by the simultaneous action on the ear of another more intense and lower sound.

2. On the Discovery of the Fact that a Sound, even when intense, cannot obliterate the Sengation of another Sound lower than it in pitch.

3. On a proposed Change in the usual Method of conducting Orchestral Music, indicated by the above discoveries.

4. Applications of the Interferences of Sonorous Sensations to Determinations of the Relative Intensities of Sounds.

THIS communication is preliminary to an elaborate paper 1 on the above subjects. For conciseness and clearness I present the few facts I have now to offer in the form of notes of experiments.

1. On the Obliteration of the Sensation of one Sound by the simultaneous action on the ear of another more intense and lower sound.

Experimental Observations on the Obliteration of one Sound by another.- Several feet from the ear I placed one of those loud-ticking spring-balance American clocks which make four beats in a second. Then I brought quite close to my ear a watch (made by Lange, of Dresden) ticking five times in the second. In this position I heard all the ticks of the watch, even those which coincided with every fourth tick of the clock. Let us call the fifth tick of the watch which coincided with one of the ticks of the clock, its fifth tick. I now gradually removed the watch from the ear and perceived that the fifth tick became fainter and fainter, till at a certain distance it entirely vanished and was, so to speak, "stamped out" of the watch $\dagger$.

Similar and more striking experiments were made with an

* Communicated by the Author.

† In the publication of this paper in 'Nature,' Aug. 10, 1876, my friend Mr. Alexander J. Ellis, F.R.S., appends the following note to the above experiment :- "The precise numbers of ticks in a second here mentioned are not necessary for roughly observing and understanding these phenomena. I observed them by a common American pendulumclock placed on a table (which increased the power of its half-second ticks), and a watch beating five times in two seconds. The Rev. Mr. Haweis informs me that he has often noticed a similar effect at night with ordinary watches. The sensation produced by the obliteration of the tick when the proper distance of tne watch from the ear has been attained, and the consequeat sudden division of the ticks into periods separated by silences, is very peculiar. It is difficult not to believe that some accident has suddenly interfered with the action of the watch instead of merely with our own sensations."-A. J, E. 
old silver watch, beating four times to the second, by causing this watch to gain about thirty seconds an hour on the clock, so that at every two minutes the ticks of the watch and clock exactly coincided. When the watch was held near the ear, every one of its ticks was heard distinctly ; but on gradually removing it.from the ear the ticks of the watch became fainter and fainter at the coincidences, and when the watch had been removed to a distance of nine inches from the ear the ticks of the watch were utterly obliterated during three whole seconds of its ticks about the time of coincidence. On removing the watch to a distance of twenty-four inches I found that I lost its ticks during nine seconds about the time of coincidence. It is here important to remark that the ticks of the clock are longer in duration, as well as lower in pitch, than those of the watch. With the watch remaining at a distance of twentyfour inches from the ear, I listened with all my attention as tick by tick the watch approached the time of coincidence. Since the ticks of the watch are shorter in duration than those of the clock, they are overlapped by the others about the time of coincidence. Hence as, so to speak, the short ticks of the watch glided tick after tick under the long ticks of the clock, I perceived that more and more of the duration of each successive watch-tick became extinguished by the tick of the clock, until only the tail end of the short tick of the watch was left audible; and at last even this also crept under the long tick of the clock, and the whole of the ticks of the watch were rendered inaudible for nine seconds, at the end of which time the front or head of the watch-tick, as we may call it, protruded beyond the clock-tick, and then slowly grew up into a complete watch-tick as before. In this succession of events the tick of the old silver watch (made by Tobias) disappears with a sharp chirp like a cricket's, and reappears with a sound like that made by a boy's marble falling npon others in his pocket. By this experiment, therefore, a gradual analysis is made of the effect of the tick of the clock on the tick of the watch, affording a beautiful illustration of the fact that one sonorous sensation may overcome and obliterate another.

Experiments to determine the relative Intensity of the Clockticks which obliterate the Watch-ticks. -The clock was placed on a post in the middle of an open level field in the country on nights when the air was calm and noiseless. The ticks of the clock became just inaudible when my ear was removed to a distance of 350 feet. The ticks of the watch became just inaudible at a distance of twenty feet. The ratio of the squares of these numbers makes the ticks of the clock about 300 times 
as intense as those of the watch. On the same nights that I made the above determinations I also put the clock on the post, and placing against my zygomatic process a slender stick graduated to inches and tenths, I stood with my ear at distances from the clock of from eight to sixteen feet, and then slid the watch above and along the stick (taking care that it did not touch it) until it reached such a distance from the ear that its fifth tick just disappeared. Knowing the relative intensities of the ticks of clock and watch when placed at the same distance from the ear, the law of the reciprocals of the squares gives the relative intensities when the clock and watch are at the several distances obtained in the above experiments. Large numbers of such experiments have been made; and the results agree perfectly well when we take into consideration, first, the difficulty thrown in the path of the determinations by the gradual fading away of the watch-ticks as they approach coincidence with the clock-ticks, and secondly, the impossibility of arriving at any result at all if the slightest noise (the rustle of a gentle breeze, the piping of frogs, the bark of a distant dog) should fall on the ear of the observer when engaged in making an experiment. The general result of the numerous experiments thus made shows that the sensation of the watch-tick is obliterated by a coincident tick of the clock when the intensity of the clock-tick is three times that of the watch-tick. This result, however, must be regarded as merely approximative, not only from the manner in which it was obtained, but from the complexity of the sounds on which the experiments were made. It is interesting, however, both as being, I believe, the first determination of this kind that has ever been made, and as having opened out a new and important field of research in physiological acoustics.

Eaperiments on the Interference of the Sensations of Musical Sounds.-Reserving the further development of my discoveries for future papers, I will now briefly describe some of the more prominent and simple phenomena which I discovered in experimenting with musical sounds. At the outset I will remove an objection always made by those versed in acoustics but unacquainted with these new phenomena. It is as follows:- "You say that one sound may obliterate the sensation of another; but are you sure that the real fact is not an alteration of the quality of the more intense sound by the action of the concurrent feebler vibration?" I exclude this objection by experimenting as follows:-An open or closed organ-pipe is sounded forcibly; and at a few feet from it is placed the instrument emitting the sound to be oblite- 
rated, which may be either a tuning-fork on its resonancebox or a closed organ-pipe communicating with a separate bellows. Suppose that in the following experiment both tuning-fork and closed organ-pipe produce a note higher in pitch than the more intense or extinguishing sound of the open organ-pipe. Now sound the fork alone strongly, and alternately shut and open its resonance box with the hand. We can thus obtain the sound of the fork in a regular measure of time. When the ear has well apprehended the intervals of silence and of sound thus produced, begin the experiment by sounding the open pipe and tuning-fork simultaneously. Now if any change is thus effected in the quality of sound emitted by the open pipe, this change cannot occur except when the fork is sounded, and hence, if it occurs at all, it must occur in the regular measure in which the fork is sounded. The following are the facts really observed. At first every time that the mouth of the box is open the sound of the fork is distinctly heard and changes the quality of the note of the open pipe. But as the vibrations of the fork run down in amplitude the sensations of its effect become less and less till they soon entirely vanish, and not the slightest change can be observed in the quality or intensity of the note of the open organ-pipe, whether the resonance box of the fork be open or closed. Indeed at this stage of the experiment the vibrations of the fork may be suddenly and totally stopped without the ear being able to detect the fact. But if instead of stopping the fork when it becomes inaudible we stop the sound of the open organ pipe, it is impossible not to feel surprised at the strong sound of the fork which the open pipe had smothered and had rendered powerless to affect the ear. If we replace the tuning-fork by a closed organ-pipe of the same pitch, the results will be the same; but in this case I adjust the intensity of the higher closed pipe to the point of extinction by regulating the flow of air from the bellows by a valve worked with a screw. The alternation of sound and silence is obtained by closing and opening the mouth of the closed pipe by the hand.

2. On the Discovery of the Fact that a Sound, even when intense, cannot obliterate the sensation of another Sound lower than it in pitch.

High Sounds cannot obliterate Low Sounds.-A new and remarkable fact was now discovered. No sound, even when very intense, can diminish or obliterate the sensation of a concurrent sound which is lower in pitch: This was proved by experiments similar to the last, but differing in having the 
more intense sound higher (instead of lower) in pitch. In this case, when the ear decides that the sound of the (lower and feebler) tuning-fork is just extinguished, it is generally discovered on stopping the higher sound that the fork, which should produce the lower sound, has ceased to vibrate. This surprising experiment must be made in order to be appreciated. I will only remark that very many similar experiments, ranging through four octaves, have been made, with consonant and dissonant intervals, and that scores of different hearers have confirmed this discovery. It is important to understand that this phenomenon depends solely on difference of pitch, and not at all on the absolute pitch of the notes. Thus a feeble $c^{\prime \prime \prime}$ (1024 double vibrations) is heard as distinctly through an intense $e^{\prime \prime \prime}$ (1280 double vibrations) as a feeble $c$ (128 double vibrations) is heard through an intense $g$ (192 double vibrations) or an intense $c^{\prime}$ (256 double vibrations).

The development of the applications and of the further illustrations of these discoveries would occupy too much space; I must therefore restrict myself to mentioning some of the most interesting. Let a man read a sentence over and over again with the same tone and modulation of voice, and while he is so doing forcibly sound a $c^{\prime}$ pipe (256 double vibrations). A remarkable effect is produced, which varies somewhat with the voice experimented on; but the ordinary result is as follows. It appears as though two persons were reading together, one with a grave voice (which is found by the combination of all the reader's real vocal sounds below $c$ in pitch, or having less than 256 double vibrations), the other with a high-pitched voice, generally squeaky and nasal, and, I need not add, very disagreeable. Of course the aspirates come out with a distressing prominence. I have observed many curious illustrations of this change in the quality of the tone of the voice, caused by the entire or partial obliteration of certain vocal components, while listening to persons talking during the sound of a steam whistle, or in one of our long, resonant American railway carriages. Experiments similar to those on the human roice can be made, with endless modifications, on other composite sounds, as those of reed-pipes, of stringed instruments, of running water, \&c. With one of my $c$ (128 double vibrations) free Grenié reeds, I get very marked results. Using as a concurrent sound an intense $c^{\prime}$ (25.6 double vibrations), I perceive the prime or fundamental simple tone $c$ to be uuaffected in intensity, while all the other partial tones (higher harmonics or overtones, as they are sometimes called) are almost obliterated, except the fifth partial (or fourth upper 
partial $e^{\prime \prime}$, of 640 double vibrations, and the sixth partial (or fifth upper partial) $g^{\prime \prime}$ (of 768 double vibrations), which come out with wonderful distinctness. The fact that the lowest, or prime partial tone in the majority of ordinary compound musical tones is strongest, is due (among other reasons) to the fact that the sensation of each partial tone of which the whole musical tone is composed, is diminished by the action on the ear of all the components or partial tones below it in pitch. Thus the higher the pitch of any component or partial tone the greater the number of lower components which tend to obliterate it. But the prime, or lowest, component partial tone is not affected by any other. Another illustration I cannot resist giving. At the end of the street in New York in which I resided, there is a large fire-alarm bell, the residual sound of which, after its higher components have disappeared, is a deep simple tone. This bass sound holds its own with total indifference to the clatter of horses, or to any sounds above it in pitch. It dies out with a smooth gradient, generally without the slighest indentation or break produced by the other sounds of the street. Indeed, in this case, as in all others where one sound remains unaffected by intense higher notes, the observer feels as though he had a special sense for the perception of the graver sound-an organ entirely distinct from that which receives the impress of the higher tones.

That one sonorous sensation cannot interfere with another which is lower in pitch is a remarkable physiological discovery, and, next after the demonstration of the fact that the ear is capable of analyzing compound musical sounds into their constituent or partial simple tones, is probably the most important addition yet made to our knowledge of the nature of hearing. It cannot fail to introduce profound modifications into the hypotheses heretofore framed respecting the mechanism and functions of the ear.

\section{On a proposed Change in the usual Method of conducting Orchestral Music, indicated by the above discoveries.}

We have seen how an intense sound may obliterate, entirely or in part, the sensations of certain partial tones or components of any musical tone, and thus produce a profound change in its quality. In a large orchestra I have repeatedly witnessed the entire obliteration of all sounds from violins by the deeper and more intense sounds of the wind instruments, the double-bases alone holding their own. I have also observed the sounds of the clarinets lose their peculiar quality of tone and consequent charm from the same cause. No doubt the conductor of the orchestra heard all his violins, 
ranged as they always are close around him, and did not perceive that his clarinets had lost that quality of tone on which the composer had relied for producing a special character of expression.

The function of the conductor of an orchestra seems to be threefold. First, to regulate and fix the time. Secondly, to regulate the intensity of the sounds produced by the individual instruments, for the purpose of expression. Thirdly, to give the proper quality of tone or feeling to the whole sound of his orchestra, considered as a single instrument, by regulating the relative intensities of the sounds produced by the various classes of instruments employed. Now this third function, the regulation of relative intensities, has hitherto been discharged through the judgment of the ears of a conductor who is placed in the most disadvantageous position for judging by his ears. Surely he is not conducting for his own personal gratification, but for the gratification of his audience, whose ears stand in very different relations from his own in respect of their distance from the various instruments in action. Is it not time that he should pay more attention to his third function, and place himself in the position occupied by an average hearer? This position would be elevated, and somewhere in the midst of the audience. The exact determination of its place would depend on various conditions which cannot now be considered. That the position at present occupied by the conductor of an orchestra has often allowed him to deprive his audience of some of the most delicate and touching qualities of orchestral and concerted vocal music I have no doubt, and I firmly believe that when he changes his position in the manner now proposed, the audience will have some of that enjoyment which he has too long kept to himself. During the past winter, in the Academy of Music at New York, and this spring at Offenbach's concerts, I fully confirmed all the foregoing surmises, by placing myself in different parts of the house to observe the different results; and my opinions were fully shared by others who have a more delicate musical organization than I can lay claim to.

In large orchestras these interferences of sonorous sensations are so multiplied and various as to be beyond our mental conception. By taking them up in detail, however, some general laws may be evolved. But it will be impossible to formulate such laws until, first, we are in possession of a quantitative analysis of the compound tones of all musical instruments (that is, until we know the relative loudness of the partial tones of which they are composed at all parts of 
their compass), and, secondly, we have determined throughout the musical scale the relative intensities of the sounds (of simple tones) when obliteration of the sensations of higher (simple) tones supervenes. The powerlessness of one sound to affect the sensation due to another sound lower than itself in pitch greatly simplifies this problem.

4. Applications of the Interferences of Smorous Sensations to Determinations of the Relative Intensities of Sounds.

Quantitative analysis of the compound tones of musical instruments is now the great desideratum of the composer. It is only after we know the relative intensities of the components of typical musical tones used in orchestral performances that we can so regulate their intensities as to give those qualities of sound which the composer desires to be heard. Thus it at once becomes evident that the instruments used in orchestral music should be very difforently constructed from those used for solos or quartets. In orchestral instruments certain characteristic upper partials (overtones, harmonics) should predominate in order to find expression in the midst of other and graver sounds. Such orchestral instruments will therefore have exaggerated peculiarities in their qualities of tone which will render them unfit to be played on alone and uninfluenced by other orchestral notes. It is surely not hopeless to anticipate that empirical rules may be attained, which will guide the musical-instrument-maker to the production of those special qualities of tone required in orchestral instruments. It is fortunate that the very phenomena of the interferences of sonorous sensations will assist in the much-desired solution of the problem of measuring the intensity of a sound (simple tone), either when existing alone or as component of an ordinary musical (compound) tone. On this suljject I am now engaged. It is evident (by way of jllustration) that, so far as concerns the measure of the relative intensities of sounds of the same pitch, this problem has already received the simplest solution by merely placing these sounds at various distances and obliterating the sensations they excite by means of a constant and standard sound of a lower pitch. But I reserve a description of this work for a more formal publication. 